\title{
APPLYING DIFFERENT LEVELS OF SOIL INFORMATION TO ESTIMATE AVAILABLE WATER CAPACITY
}

\author{
AN, L. S. ${ }^{1 *}-$ LIAO, K. H. ${ }^{2}-$ LIU, C. ${ }^{3}$ \\ ${ }^{1}$ Department of Environmental Science, Anqing Normal University \\ 1318 North Jixian Road, Anqing 246011, P.R. China \\ ${ }^{2}$ Key Laboratory of Watershed Geographic Sciences \\ Nanjing Institute of Geography and Limnology, Chinese Academy of Sciences \\ 73 East Beijing Road, Nanjing 210008, P.R. China \\ ${ }^{3}$ The 326 Geological Team, Bureau of Geology and Mineral Explorition of Anhui Province \\ 21 South Linghu Road, Anqing 246003, P.R. China \\ (phone: +86-556-5708192; fax: +86-556-5708192) \\ *Corresponding author \\ e-mail: als00316@163.com \\ (phone:+86-556-5708192) \\ (Received $3^{\text {rd }}$ Jul 2016; accepted $6^{\text {th }}$ Oct 2016)
}

\begin{abstract}
Soil available water capacity (AWC) plays an important role in soil and water resource management, and is time-consuming and expensive to measure over large areas. AWC is often predicted with pedotransfer functions (PTFs) using easily measured soil properties (e.g., texture, bulk density and organic matter content). This study investigated the effectiveness of using neural network based-ROSETTA PTF to estimate AWC from four hierarchical levels of soil information: textural class $(\mathrm{R} 1)$, texture (R2), texture and bulk density (R3), texture, bulk density, and water content at $-33 \mathrm{kPa}\left(\theta_{-33}\right)$ and $-1500 \mathrm{kPa}\left(\theta_{-1500}\right)\left(\theta_{-33}\right.$ and $\theta_{-1500}$ derived from Gupta-Larson PTF) (R4). A comprehensive dataset containing 58 soil samples collected from eastern China were used for evaluation. Results show that all the ROSETTA models except R1 estimate reliably the AWC. R2 and R3 produce similar estimates, both of which have only slightly poorer performance than R4. In this case soil texture is considered to be the most important soil property influencing AWC, making negligible the effects of the bulk density and organic matter content. It can be concluded that measuring soil texture as inputs for ROSETTA is the most affordable and reasonable approach to predict AWC in the study area.
\end{abstract}

Keywords: soil water content, pedotransfer functions, ROSETTA, soil texture, water resource management

\section{Introduction}

Available water capacity (AWC) is the water retained in soils between field capacity ( $\mathrm{FC}$, water content at $\left.-33 \mathrm{kPa}, \theta_{-33}\right)$ and permanent wilting point ( $\mathrm{PWP}$, water content at $\left.-1500 \mathrm{kPa}, \theta_{-1500}\right)$. AWC is a component of the water and energy balances of terrestrial biosphere, and is required in ecological studies to establish the response of plant or animal species or communities to environmental conditions (Cazemier et al., 2001). The availability of soil moisture controls the rates of evaporation and transpiration, which in turn can have a major impact on climate. It also controls hydrologic processes such as groundwater recharge, infiltration and overland flow. Soil water holding capacity is one of the most important soil factors for plant growth, 
influencing carbon allocation, nutrient cycling, and the rate of photosynthesis. Specially, AWC is considered to be an important indicator of soil quality since plant growth relies on water for delivery of nutrients in solution and an indispensable parameter in different hydrologic models like the SWAT (Arnold et al., 1993) and TOPMODEL models (Beven and Freer, 2001). Therefore, knowledge of AWC is very essential for hydrological, ecological and agricultural management in a particular region. However, it is time-consuming and costly to measure AWC over large areas. Pedotransfer functions (PTFs) have often been used to estimate water retention at FC and PWP from easily measurable basic soil properties, such as particle size distribution, bulk density (BD) and organic matter (OM) content (Pachepsky and Rawls, 2004; Nemes et al., 2011). The regression was initially used to develop the PTFs (Gupta and Larson, 1979; Rawls et al., 1982). Recently, Schaap et al. (2001) applied the artificial neural network to develop the ROSETTA PTF for a convenient application. Because neural network is able to capture and simulate the complex relationships between water retention points and basic soil properties, it outperformed regression analysis (Merdun et al., 2006).

Although PTFs offer a means to predict AWC, it is still necessary to determine which level of soil information would be sufficient for use with PTFs. Such an analysis can minimize soil measurements. However, to our knowledge very little research has been conducted on this issue, especially in China. The objective of this study was to compare ROSETTA-predicted AWC against observations with four hierarchical levels of soil information.

\section{Materials and methods}

\section{Soil sampling and analysis}

A total of 58 undisturbed soil samples were collected from surface horizon (0-20 $\mathrm{cm}$ ) in agricultural regions of Qingdao City, eastern China. The land use is dominated by the intensive dual-cropping systems of winter wheat and summer maize. The main soil texture types were sandy loam (26 samples) and loam (32 samples) according to the USDA classification.

FC and PWP were measured using pressure plates following the method of Klute (1986). Pressure plates apparatus are very common experimental devices utilized to measure the soil water retention curve. Solone et al. (2012) have demonstrated that no significant differences in measurements made by the pressure plates apparatus as compared to the dew point method were detected for coarse textured soils (e.g., sandy loam and loam in this study). Therefore, we consider that the measurement error has little influence on the final results. The contents of sand $(0.05-2 \mathrm{~mm})$, silt $(0.002-0.05$ $\mathrm{mm})$ and clay $(0-0.002 \mathrm{~mm})$ particles in soils were measured with the pipette method, and are listed in Table 1. The BD was determined by oven-drying soil samples at $105^{\circ} \mathrm{C}$ for $24 \mathrm{~h}$. The soil $\mathrm{OM}$ content was estimated from the organic carbon content determined by the Walkley-Black wet oxidation method using a constant 1.724 for transformation (Nelson et al., 1996). Figure 1 shows a substantial variation of the soil clay and OM contents. 
Table 1. Statistics of measured soil particle size distributions

\begin{tabular}{ccccc}
\hline & Min (\%) & Max (\%) & Mean (\%) & SD (\%) \\
\hline Sand & 34.33 & 70.84 & 50.89 & 8.66 \\
Silt & 19.19 & 49.42 & 33.22 & 6.03 \\
Clay & 7.62 & 27.00 & 15.89 & 4.72 \\
\hline
\end{tabular}

SD = standard deviation

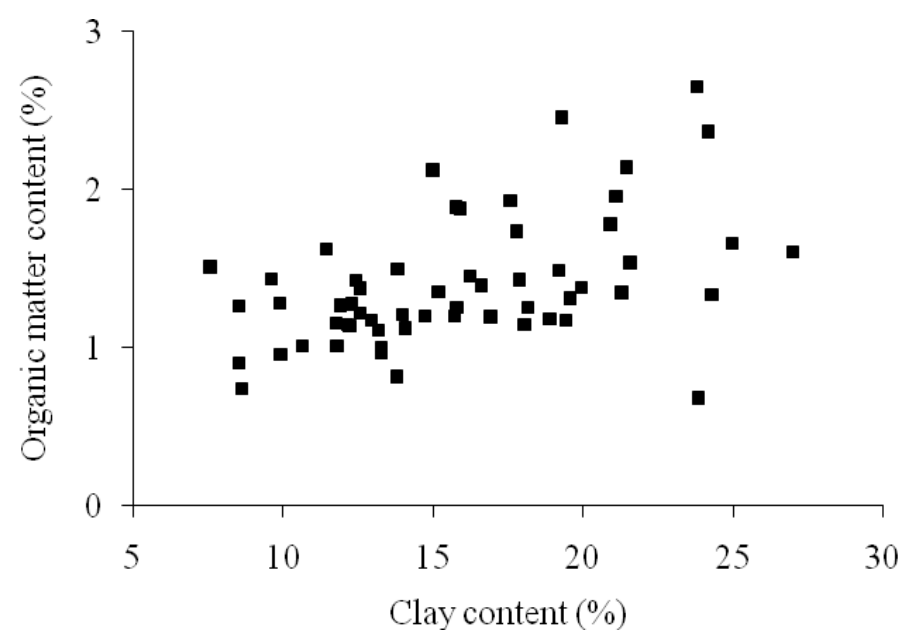

Figure 1. Scatter plot of soil organic matter and clay contents of the investigated soil samples.

\section{ROSETTA model}

ROSETTA has the ability to predict FC and PWP from texture, BD and one or two retention points (Schaap et al., 2001). In this study, a hierarchical method was applied using ROSETTA, with four levels of soil information used as inputs: textural class (R1), texture (R2), texture and BD (R3), texture, BD, and predicted FC and PWP from texture, $\mathrm{BD}$ and OM using the formula offered by Gupta and Larson (1979).

\section{Evaluation criteria}

The prediction accuracy of the four ROSETTA models was evaluated by the mean error (ME) and the root mean squared error (RMSE):

$$
M E=\frac{\sum_{i=1}^{n}\left(A W C_{m}-A W C_{p}\right)}{n}
$$




$$
R M S E=\sqrt{\frac{\sum_{i=1}^{n}\left(A W C_{m}-A W C_{p}\right)^{2}}{n}}
$$

(Where, $n$ is the number of samples used for evaluation; $A W C_{m}$ is the measured value; $A W C_{P}$ is the predicted value; $M E$ is a measure of the overall forecast bias, while the $R M S E$ provides a measure of accuracy).

\section{Results}

Statistics of the measured and ROSETTA-predicted AWC from four levels of soil information have been conducted and are listed in Table 2. The mean and standard deviations (SDs) of the predictions are 0.212 and $0.0240 \mathrm{~cm}^{3} \mathrm{~cm}^{-3}$ for $\mathrm{R} 1,0.186$ and $0.0227 \mathrm{~cm}^{3} \mathrm{~cm}^{-3}$ for R2, 0.182 and $0.0219 \mathrm{~cm}^{3} \mathrm{~cm}^{-3}$ for R3, and 0.189 and $0.0253 \mathrm{~cm}^{3}$ $\mathrm{cm}^{-3}$ for R4, respectively. By contrast, the mean and SDs of the observations are 0.181 and $0.0395 \mathrm{~cm}^{3} \mathrm{~cm}^{-3}$, respectively. The MEs and RMSEs are -0.0310 and $0.0468 \mathrm{~cm}^{3}$ $\mathrm{cm}^{-3}$ for R1, -0.0050 and $0.0322 \mathrm{~cm}^{3} \mathrm{~cm}^{-3}$ for R2, -0.0053 and $0.0321 \mathrm{~cm}^{3} \mathrm{~cm}^{-3}$ for R3, and -0.0057 and $0.0313 \mathrm{~cm}^{3} \mathrm{~cm}^{-3}$ for $\mathrm{R} 4$, respectively.

Table 2. Statistics of measured and ROSETTA-predicted available water capacity used for assessment

\begin{tabular}{|c|c|c|c|c|c|c|}
\hline \multirow{2}{*}{ Model } & \multicolumn{4}{|c|}{ Summary statistics $\left(\mathrm{cm}^{3} \mathrm{~cm}^{-3}\right)$} & \multirow{2}{*}{ ME } & \multirow{2}{*}{ RMSE } \\
\hline & Min & Max & Mean & SD & & \\
\hline \multicolumn{7}{|c|}{ Measured available water capacity } \\
\hline & 0.096 & 0.257 & $0.181 \mathrm{a}$ & 0.0395 & & \\
\hline \multicolumn{7}{|c|}{ ROSETTA-estimated available water capacity } \\
\hline $\mathrm{R} 1$ & 0.186 & 0.234 & $0.212 b$ & 0.0240 & -0.0310 & 0.0468 \\
\hline $\mathrm{R} 2$ & 0.138 & 0.254 & $0.186 a$ & 0.0227 & -0.0050 & 0.0322 \\
\hline R3 & 0.136 & 0.247 & $0.182 \mathrm{a}$ & 0.0219 & -0.0053 & 0.0321 \\
\hline R4 & 0.126 & 0.263 & $0.189 \mathrm{a}$ & 0.0253 & -0.0057 & 0.0313 \\
\hline
\end{tabular}

$S D=$ standard deviation, $M E=$ mean error, $R M S E=$ root mean squared error. The lowercase after the number indicate the significances. Numbers with the same lowercase are not significant (Paired samples T test, $P<0.05)$.

\section{Discussion}

From Table 1, a significant difference in sample means could only be found between measured and R1-predict AWC by using the paired samples $T$ test. This suggests that R1 provides worse estimates than the other three ROSETTA models. SDs are generally 
smaller for the ROSETTA predictions than for the observations, which implies a kind of smoothing effect concerning the reference data caused by using the ROSETTA model. Romano and Santini (1997) also observed smoothing effect when using PTFs to predict soil water retention points.

The MEs for the four ROSETTA models are less than 0, which indicates that they generally overestimate the AWC values. The RMSE of R1 is substantially larger than those of the other three models, implying that textural class as inputs for ROSETTA is not enough to estimate AWC with acceptable accuracy. The accuracy of ROSETTA is significantly improved by introducing more complexity levels of soil information. It is found that R2 and R3 produce similar RMSE values, both of which give only slightly greater RMSE values than R4. This implies that soil texture is the main soil property influencing AWC, making negligible the effects of the soil BD and OM content. Pachepsky and Rawls (2004) also proposed that soil texture has the greatest effect on AWC among soil properties. Therefore, measuring soil texture for ROSETTA (R2) is the most affordable and reasonable approach to estimate AWC in the study area.

From Figure 2, the predicted AWC by R2 is similar to the measured AWC, with a determination coefficient of 0.40 . The observed deviations can partly be attributed to the extrapolative use of the ROSETTA model. Although the ROSETTA model R2 overestimates the AWC values, the RMSE value is only $0.032 \mathrm{~cm}^{3} \mathrm{~cm}^{-3}$ for this method. Therefore, the prediction accuracy of R2 is considered to be acceptable. Errors in soil water retention points determined with pressure plates might also contribute to the differences between observed and predicted AWC (Bittelli and Flury, 2009). However, addressing this aspect is beyond the scope of this study.

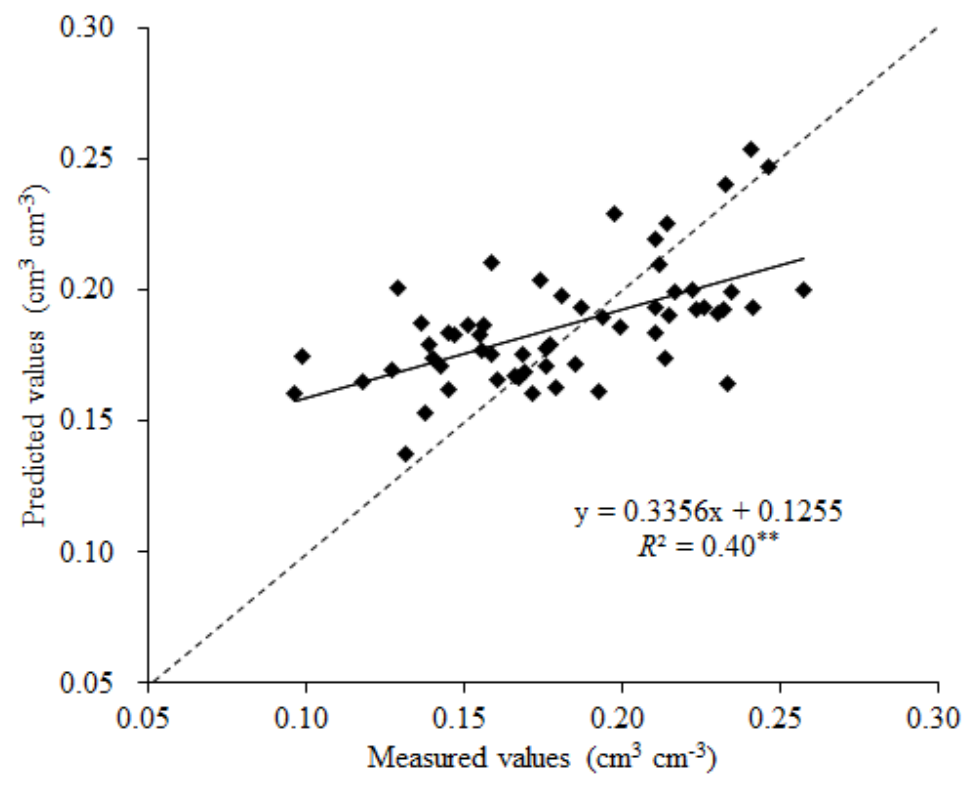

Figure 2. Measured versus ROSETTA-predicted values of available water capacity from soil sand, silt and clay contents. $* *$ means significant at $1 \%$ probability level. $N=58$.

\section{Conclusions}

This study used 58 soil samples to evaluate the effectiveness of using the ROSETTA PTF to estimate AWC from four hierarchical levels of soil information. Statistical 
comparisons show the greatest difference between measured and predicted AWC with textural class (R1). Good agreement between observed and predicted AWC was found using the more extended set of soil information. Since only two soil texture classes were considered in this study, assessments on other soil texture types are needed in future work. Especially, we consider that the ROSETTA PTF could also be valid for relatively coarse textured soils in other regions. However, the performance of this method is still needed to be tested for those fine textured soils.

Acknowledgements. This work was supported by the project of Natural Science Research for Colleges and Universities of Anhui Province, China (grant KJ2016A424, AQKJ2014B022).

\section{REFERENCES}

[1] Arnold, J. G., Allen, P. M., Bernhardt, G. (1993): A comprehensive surface-groundwater flow model. - Journal of Hydrology 142(1-4): 47-69.

[2] Beven, K., Freer, J. (2001): A dynamic TOPMODEL. - Hydrological Processes 15: 1993-2011.

[3] Bittelli, M., Flury, M. (2009): Errors in water retention curves determined with pressure plates. - Soil Science Society of America Journal 73: 1453-1460.

[4] Cazemier, D.R., Lagacherie, P., Martin-Clouaire, R. (2001): A possibility theory approach for estimating available water capacity from imprecise information contained in soil databases. - Geoderma 103: 113-132.

[5] Gupta, S. C., Larson, W. E. (1979): Estimating soil water retention characteristics from particle-size distribution, organic matter percent, and bulk density. - Water Resources Research 15: 1633-1635.

[6] Klute, A. (1986): Water Retention: Laboratory methods. - In: Methods of soil analysis: Part 1, Physical and mineralogical methods, 2nd edition (Ed. A. Klute), pp. 635-662. Agronomy Monograph No. 9, American Society of Agronomy and Soil Science Society of America, Madison, Wisconsin.

[7] Merdun, H., Çınar, Ö, Meral, R., Apan, M. (2006): Comparison of artificial neural network and regression pedotransfer functions for prediction of soil water retention and saturated hydraulic conductivity. - Soil \& Tillage Research 90: 108-116.

[8] Nemes, A., Pachepsky, Ya. A., Timlin, D. J. (2011): Toward improving global estimates of field soil water capacity. - Soil Science Society Of America Journal 75: 807-812.

[9] Nelson, D. W., Sommers, L. E., Sparks, D., Page, A., Helmke, P. (1996): Total carbon, organic carbon, and organic matter. - Methods of soil analysis Part 3-chemical methods: 961-1010.

[10] Pachepsky, Ya. A., Rawls, W. J. (2004): Status of pedotransfer functions, in Pachepsky, Ya. A., Rawls, W.J. (eds.): Development of Pedotransfer Functions in Soil Hydrology. - Elsevier, Amsterdam pp: vii-xviii.

[11] Rawls, W. J., Brakensiek, D. L., Saxton, K. E. (1982): Estimation of soil water properties. - Transactions of the American Society of Agricultural Engineers 25: $1316-1320,1328$.

[12] Romano, N., Santini, A. (1997): Effectivenss of using pedo-transfer functions to quantify the spatial variability of soil water retention characteristics. - Journal of Hydrology 202: 137-157.

[13] Schaap, M. G., Leij, F. J., van Genuchten, M. T. (2001): ROSETTA: a computer program for estimating soil hydraulic parameters with hierarchical pedotransfer functions. - Journal of Hydrology 251(3-4): 163-176. 
[14] Solone, R., Bittelli, M., Tomei, F., Morari, F. (2012): Errors in water retention curves determined with pressure plates: Effects on the soil water balance. -Journal of Hydrology 470: 65-74. doi:DOI 10.1016/j.jhydrol.2012.08.017.

\section{ELECTRONIC APPENDIX}

This article has an electronic appendix with field data. 